\title{
Descobrindo a colonização portuguesa e o tráfico de escravos
}

\author{
Discovering the Portuguese colonization and the \\ trafficking of slaves
}

\author{
En découvrant la colonisation portugaise et le trafic \\ d'esclaves
}

Fernanda Inacio da ROSA

\section{RESUMO}

Este depoimento refere-se à regência realizada em uma escola pública no município de Itapevi, região metropolitana de São Paulo. A temática desenvolvida na aula foi o tráfico de escravos africanos.

Palavras-chave: Crianças, Colonização, Escravos, Tráfico.

\section{ABSTRACT}

This testimony is about the didactical work carried out in a public school in Itapevi, a city located in the metropolitan region of Sao Paulo. Trafficking slaves from Africa was the developed subject.

Index terms: Children, Colonization, Slaves, Trafficking.

\section{RÉSUMÉ}

Ce témoignage est le résultat d'un travail fait dans une école publique de la ville d'Itapevi, région métropolitaine de São Paulo. Le thème développé a été le trafic d'esclaves africains.

Mots-clés: Enfants, Colonisation, Esclaves, Trafic. 


\section{Introdução}

Minha experiência acerca da transposição didática - referente à participação em "espaço de criação" coordenado pela professora doutora Nilce da Silva acerca das principais características do mundo lusófono - realizou-se em uma escola pública da periferia da cidade de Itapevi, região metropolitana de São Paulo, nos dias 10 e 12 de junho de 2008.

A escola está localizada no bairro Jardim Vitápolis. Ali estudaram muitos dos pais dos alunos e estima-se que estejam estudando ali a terceira geração de algumas famílias. Atualmente, a escola, que trabalha exclusivamente com ensino fundamental I, funciona em três períodos: manhã, tarde e noite. Durante o dia são atendidas as crianças de seis a 11 anos, em média; e, o período noturno atende aos adultos na Educação de Jovens e Adultos (EJA). A escola atende crianças oriundas de diversas regiões do Brasil, sendo que a maioria delas é da região nordeste.

Este ano, como relatou uma professora da referida unidade de ensino, a escola tem uma novidade: foi o primeiro ano que a escola começou a receber crianças dos acampamentos dos ciganos que estão instalados bem próximos a escola. Antes dos ciganos, a escola só havia atendido a um caso diferente de sua realidade: receberam uma menina, cujos pais eram praticantes do candomblé e ela deveria ir vestida a caráter para a escola e, algumas vezes, com os cabelos raspados após algum ritual.

Antes de elaborar uma aula que contribuísse para o enriquecimento de algum tema já trabalhado na sala de aulas destas crianças, resolvi que a observação das relações entre professor-aluno e alunos entre si seria um ótimo 
caminho para coleta das necessárias informações. Escolhi as crianças maiores, da $4^{\circ} \mathrm{D}$.

Ao contrário do que muitos poderiam pensar, estas crianças não apresentam muitas dificuldades em se relacionar com pessoas de diferentes regiões e etnias/raças. Na sala observada, apenas 30\% dos alunos são negros, ou seja, 12 de 40 alunos.

Durante a observação, pude presenciar uma cena no ensaio da festa junina que direcionou totalmente o tema da aula sobre a qual eu prepararia e realizaria com estes alunos. A saber: as crianças ensaiavam uma musica country que era dançada aos pares. Na hora em que a professora começou a organizar a dança, um dos alunos diz bem alto para que todos pudessem ouvir: "Eu não quero dançar com essa negrinha, professora!” [sic]. O curioso é que esse mesmo menino também era negro. Quando questionado sobre o porquê fizera aquilo com a colega de sala, o menino respondeu que, assim como muitas pessoas o chamavam de neguinho sem-vergonha perto de sua casa, ele queria fazer com que outras pessoas sentissem a mesma angústia que ele sentia.

Depois de muito pensar sobre os possíveis temas que poderiam ser abordados por mim em sala de aula, resolvi que trazer para os alunos, principalmente para o menino em questão, que o mesmo desprezo foi sentido por muitos negros escravizados durante o período colonial no Brasil, era de grande interesse.

Após dois dias da referida observação, voltei para a mesma sala de aula. Apresentei-me formalmente para os alunos e expliquei que, naquele dia, iríamos conversar um pouco sobre a Colonização Portuguesa no Brasil e em alguns países africanos. 
Cada dupla de alunos recebeu um mapa do mundo para que pudéssemos localizar os continentes e países em questão. Começamos com questões bem básicas: localização do Hemisfério Norte e Sul a partir da linha do Equador, e, dentro da linguagem geográfica, a divisão do mundo em Ocidental e Oriental, tomando como referência o Meridiano de Greenwich. Localizamos cada um dos continentes: América; Ásia; África; Europa e Oceania. Localizamos o Brasil usando como referencia a linha do Equador e o Meridiano de Greenwich; e o mesmo fizemos com a África e outros países que foram perguntados pelos alunos curiosos pelo saber.

Durante a localização, surgiu uma dúvida muito pertinente e que merece ser citada. Um dos alunos questionou a diferença entre o Brasil e a África, já que ambos, no mapa que utilizávamos para nossos estudos em classe, eram quase do mesmo tamanho. Uma das alunas pediu a palavra e respondeu a questão do colega dizendo que a diferença é que o Brasil é um país e a África um continente. Outro colega perguntou, em seguida, o que era um continente. A mesma menina respondeu que continente era um agrupamento de países, uma das cinco divisões da Terra. Este exercício foi pensado para que, durante a exposição sobre a colonização e o trafico negreiro, o alunos soubessem localizar no mapa os países em questão, e exigiu a participação de todos os presentes na sala de aula.

Iniciei falando sobre Portugal. Pedi para que eles o localizassem no mapa e me respondessem em qual continente o país estava localizado. Após todos observarem a posição geográfica, comecei a expor o que favoreceu o país a se tornar uma grande potência marítima no século XV. Pensei que seria muito rico falar sobre as colônias africanas, para falar do Brasil, e, finalmente, chegar ao tráfico de escravos. Assim, falei sobre a conquista do litoral africano, e que, 
após algum tempo, alguns desses territórios transformaram-se em grandes centros comerciais. Assim, os portugueses concentraram-se na exploração no marfim, escravos e ouro do continente africano.

Conversamos sobre a chegada de Bartolomeu Dias no Cabo da Boa Esperança e a chegada do navegador Vasco da Gama em Calicute, na Índia. Por fim, falamos de Pedro Álvares Cabral que em 22 de abril de 1500 aporta na Terra de Santa Cruz (Brasil).

Achei importante falar sobre o início da colonização, período em escravizaram os nativos da terra, e que, os escravos africanos começaram a chegar às terras brasileiras, e a substituir os índios, no século XVI. Acrescentei também que, para os portugueses, existiam dois tipos de negros: os da terra (índios) e os da guiné (africanos).

Os alunos participavam intensamente do assunto abordado. Eles já possuíam conhecimento sobre o "descobrimento" do Brasil e tudo que eu dizia em relação à colonização portuguesa era somente para completar o tema já conhecido por eles.

Perguntei-lhes, então, sobre o que eles pensavam acerca da venda de pessoas. Muitos achavam um absurdo, dizendo que nunca uma pessoa poderia vender a outra porque era crime ou que a mãe e o pai nunca deixariam isso acontecer com eles. Assim, começamos a conversar sobre o tráfico de escravos trazidos pelos portugueses ao Brasil de países como Guiné (século XVI), Congo e Angola (século XVII e XVIII) e Moçambique (século XVIII e XIX). Falei que os escravos sofriam durante a longa viagem até o Brasil. Além disso, viviam distante de sua terra, de sua família. Disse que, apesar de tudo, muitos 
resistiam à escravidão e que esta durou, oficialmente no Brasil, durante mais de três séculos.

Um dos alunos acrescentou que muita da nossa cultura foi trazida pelos escravos, como a capoeira. Outro disse que a macumba, que era coisa do demônio, também fora trazida pelos escravos. Neste momento, pude intervir e dizer que os cultos, como o candomblé, são mais uma forma de os povos manifestarem a sua cultura, assim como os católicos rezam a missa. Outro aluno associou o tráfico de escravos com o tráfico de drogas, dizendo que quem traficava os escravos deveria ser tão rico, naquela época, quanto os traficantes de droga de hoje. A professora também lembrou que muitos trabalhadores hoje também vivem na condição de escravos, de trabalho forçado; além da venda ilegal de crianças e do tráfico de mulheres para se prostituírem em outros países.

Perguntei se eles sabiam quais eram as semelhanças entre o Brasil e alguns países do litoral africano. Alguns responderam que o elemento em comum eram os negros. Outros responderam que era a colonização portuguesa.

Questionei se, por acaso, algum dia eles viajassem para algum desses países, qual seria o idioma que eles deveriam utilizar. Todos ficaram pensativos, até que um menino disse que havia assistido em um programa de televisão que existia um lugar na África que também falava português, assim como nós. Expliquei, então, que os países colonizados por Portugal, ainda que o idioma oficial é o português, apenas uma parte da população conhece e sabe se comunicar neste idioma. Alguns ficaram um tanto deslumbrados com a possibilidade de pessoas que moram tão longe falarem de uma maneira que eles pudessem entender. 
Para finalizar, li para as crianças alguns fragmentos do poema Navio Negreiro, de Castro Alves (1847-1871), que viveu durante o período da escravidão no Brasil. Pedi para que prestassem atenção aos horrores trazidos na poesia, de como deveria ser a viagem dos escravos até a colônia.

No final deste trabalho, perguntei ao menino que ofendeu sua colega de sala se somente ele, sujeito negro, havia sofrido humilhações por pessoas que acreditavam ser melhores do que as demais por terem a cor da pele diferente. Ele pediu desculpas a colega e, num tom bem confiante, disse que contaria a todos que fazia parte de um povo que conseguiu resistir à escravidão, lutando pelos seus direitos e, principalmente, pelo respeito, pois, independente da cor, todos somos seres humanos.

\section{Referências bibliográficas}

ALVES, Castro (1979). Navio negreiro. Salvador: UFBA.

\section{Autora}

\section{Fernanda Inacio da Rosa}

Graduanda em Pedagogia pela Faculdade de Educação da Universidade de São Paulo, onde realizou iniciação científica no Centro de Memória. Trabalha numa escola de educação infantil no município de Itapevi.

Contato: fernandainacio@ hotmail.com 


\section{Como citar este depoimento:}

ROSA, Fernanda Inacio da. Descobrindo a colonização portuguesa e o tráfico de escravos. Revista ACOALFAplp: Acolhendo a Alfabetização nos Países de Língua portuguesa, São Paulo, ano 3, n. 6, 2009. Disponível em: $<$ http://www.acoalfaplp.net>. Publicado em: março 2009.

Recebido em junho de 2008/ Aprovado em julho de 2008 